particularly in ointments and salves. Concurrently with remedies likely to be beneficial to the patient, nauseous and foul-smelling substances such as human and animal excrement were employed with the object of driving out the demon, a practice frequently resorted to in the Middle Ages. Certain ceremonials were also carried out, such as the tying of knots in a cord to symbolise imprisonment of the demon after the disease had been expelled from the body. The study of these texts is of interest not only on their own account, but also because they show the influence of Assyrian medicine on the medicine of the Jews, in which the idea of demoniac possession in disease, incantations, and magic rites played so important a part.

The Subject Index to Periodicals, 1920. K: Science and Technology. Issued by the Library Association. Pp. II6. (London: Grafton and Co., I923.) $25^{s}$. net.

WE congratulate the Library Association on the publication of this index of scientific papers published in I920, being a continuation of similar work already done for previous years. The present list is quite up to the high standard which we have been led by previous issues to expect. It contains no less than 5092 entries taken from 304 periodicals. The greater part of the papers indexed are from British and American journals, but many important entries from German and French sources also appear.

The range of subjects dealt with under "Science and Technology " is naturally very wide. It includes in its scope such headings as anatomy, bacteria, birds, caviare, chemistry, crystallography, electric furnaces, flies, games and sports, geology, gunnery, mines, motor cycles, plants, and shipbuilding. The titles of the papers are indexed under appropriate headings such as these, but it may happen that the actual title fails to give a sufficient indication of the contents of a paper. In such cases the editors have added a few words of their own, within square brackets, to indicate the actual subject-matter of the paper. These concise notes are a great addition to the value of the compilation.

We observe that the Library Association has formed a Bureau of Information to enable subscribers to obtain, in advance of publication, copies of entries under any specified heading. It is at least three years since the articles now indexed were published, and even if rapidity of publication could be somewhat increased, there must be always a large number of papers that have appeared too late for inclusion in the last volume. If the Bureau is able to provide inquirers with anything approaching full particulars of recent work on any subject of inquiry, it will be doing exceedingly useful work. Hitherto, schemes of this kind have been impeded by financial considerations. Happily, the Library Association may surmount this difficulty.

Chemical Synonyms and Trade Names: a Dictionary and Commercial Handbook. By William Gardner. Pp. iv +27 . (London : Crosby Lockwood and Son, r924.) 25 s. net.

THIs is an extremely useful volume, giving in alphabetical order a list of about 14,000 definitions and crossreferences of chemicals and substances used in the chemical and allied industries, particularly alloys, commercial chemicals, drugs, dyestuffs, minerals, explosives, and pigments. The object is to provide a ready-reference book to the chemist and technologist for all the synonyms and trade names in more common use, giving at a glance their chemical constitution.

The author has certainly succeeded to a very remarkable degree in his difficult and laborious task, and we can recommend the book. Naturally, with such a vast subject, it is easy to find omissions or somewhat unsatisfactory definitions. Thus, to take a few examples at random, the description of "petrol" is very skimpy, and at least the boiling-point of the petrol fraction and the main hydrocarbon constituents should be given. There is nothing to be found, also, under the title " amido-naphthol sulphonic acids," although certainly " $\mathrm{H}$. acid" and "Gamma acid" are under their respective headings.

The complicated dyestuff portion of the book is, however, as a rule excellent, although "benzidine," " dianisidine," and " tolidine" are missing.

The printing and the paper are good, but in a work essentially for hasty reference purposes the binding might have been better, with advantage.

\section{Alternating Current Bridge Methods for the Measurement of Inductance, Capacitance, and Effective Resistance at Low and Telephonic Frequencies: a Theoretical and Practical Handbook for the Use of Advanced Students. By B. Hague. (The Specialists' Series.) Pp. xiii + 302. (London: Sir Isaac Pitman and Sons, Ltd., I923.) I 5 s. net.}

DURING the last thirty years a very large number of papers has been published on alternating-current bridge methods of measuring inductance and capacity. For adjusting apparatus in radio work an accurate knowledge of these quantities is required. A large and continually increasing number of methods has also been evolved for measuring these quantities. Hence there is a demand for a book which will describe only the most suitable methods applicable to the various cases. To electricians with a sound knowledge of alternating-current work we can recommend this book, although in our opinion it could have been improved by omitting several of the methods and at least half the references.

We agree with the author that the word "capacity" must be very carefully used. When there are a series of insulated bodies, he uses certain coefficients which he calls the "earth-capacities" and the "intercapacities" respectively. They are not the same as Maxwell's capacity coefficients, but they are perhaps more convenient in practical work. A proof is given that any two of them have a "mutual" capacity coefficient. This proof, however, is merely another statement of the author's definition, itself founded on several electrostatic theorems which are not mentioned.

Time and Weather by Wireless. By W. G. W. Mitchell. Pp. xii + r25. (London: The Wireless Press, Ltd.; New York: Wireless Press, Inc., r923.) 3s. 6 d. net. GREAT advances have been made recently both in distributing the correct time and in distributing meteorological data by broadcasting. In addition, Greenwich time can be obtained with a maximum

$$
\text { NO. } 284 \text { I, VOL. I I } 3]
$$

